\title{
Study on Cooperative Culture, Network Power and Knowledge Flow from the Perspective of Enterprise Innovation Network Management
}

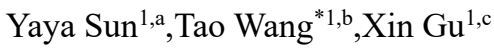 \\ ${ }^{1}$ Business School, Sichuan University Chengdu soft Creative Intelligence Research Association Chengdu, China
}

\begin{abstract}
Efficiently development of enterprise innovation networks is inseparable from integrated innovation processes such as knowledge sharing and transfer. Knowledge flow is a core network activity that is highly dependent on the cultural and structural environment. As an informal governance mechanism, cooperative culture affects the stability and durability of relationship between members. Perfectly cooperative cultural mechanism is the key to promoting knowledge flow in innovation networks. The purpose of this paper is to explore whether and how cooperative culture and network power affect knowledge flow in innovation networks. This paper finds that cooperative culture, network power has a positive effect on knowledge flow, which was obtained by using SEM method based on 227 questionnaire survey samples of enterprises. Furthermore, this paper also uses fuzzy quantitative comparative analysis (fsQCA) to study how cooperative culture and network power work together on knowledge flow. This study finds out three paths that lead to high knowledge flow, which are composed of the elements of cooperative culture and network power. The three paths are knowledge reciprocity-oriented, cooperative culture-oriented and cultural knowledge fitoriented respectively. These findings are of great significance for promoting the management of innovation networks.
\end{abstract}

\section{Introduction}

With the advent of the knowledge economy era, the innovation activities of enterprises gradually manifest themselves as networking and globalization. Innovation requirements are getting higher, enterprises relying only on their own innovation capabilities can no longer meet the needs of social and economic development. They can overcome uncertainty only by establishing cooperative and innovative relationship with other members. Therefore, the innovation network came into being. In 1989, Imai and Baba first put forward the concept of enterprise innovation networks, and believed that an enterprise innovation network is a basic institutional arrangement for enterprises to deal with innovative systems ${ }^{[1]}$. The main purpose of an enterprise to establish or join an innovation network is to obtain knowledge and resources that it lacks. The distinctive feature of the innovation network is the knowledge interaction between members. As the core activity of innovation network, the stability and persistence of knowledge flow between members directly affect the network innovation performance. Knowledge flow is the key to improving the competitive advantage and realizing the sustainable development of innovation networks.

The cooperative relationship between network members will directly affect knowledge flow. As an informal governance mechanism, it affects the durability and stability of relationship between members. Cooperative culture refers to a soft environment that is shared by the group and that restricts its economic strategy and goal formulation, including the common values and behavioral concepts generally accepted by the group ${ }^{[2]}$. It is a prerequisite for establishing a cooperative relationship between members ${ }^{[3]}$. Cooperative culture promotes the establishment of a high degree of trust and cooperative bonds between enterprises ${ }^{[4]}$, so as to promote exchange and learning among members and improve the flow and sharing of tacit knowledge in innovation networks ${ }^{[5]}$.

In addition, differences in the location and power of network members will also have an impact on knowledge flow. Sun (2014) ${ }^{[6]}$ points out that the differences in the location and power allocation of enterprises guide and influence the cooperative relations, behaviors among network members. The concept of network power was first proposed by Grewal ${ }^{[7]}$ who pointed out that network power is the ability of the subject of rights to influence the behavior of other subjects for their own interests. The core enterprise plays the role of management and guidance to knowledge flow, and uses its network power to manage and rationally deploy knowledge flow ${ }^{[8]}$. Falzon $(2018)^{[9]}$ indicates that enterprises with higher network power have higher relationship and integration capabilities, which can ensure the dynamic stability of innovation networks and promote knowledge sharing. It can be seen that network

\footnotetext{
a1542704522@qq.com

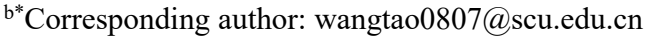

cruanchuangzhiye@qq.com
} 
power plays an important role in coordinating knowledge flow in innovation networks.

The above researches reveal the role of cooperative culture and network power in promoting knowledge flow. Improving the efficiency of knowledge flow is the key to the efficient operation and sustainable development of innovation networks. However, there are still some shortcomings in existing research. There are few studies on cooperative culture and network power, is there a certain linear relationship between cooperative culture, network power and knowledge flow, as well as the specific path through which cooperative culture and network power jointly influence knowledge flow is still a challenge. Based on the above analysis, firstly, this paper uses SEM method to verify the linear relationship between cooperative culture, network power and knowledge flow. In addition, this study uses fsQCA to analyze the influence of different element combinations of cooperative culture and network power on knowledge flow, so as to find ways to improve the efficiency of knowledge flow.

\section{Literature and Hypotheses}

\subsection{The Influence of Cooperative Culture on Knowledge Flow}

Knowledge flow in innovation networks refers to a series of knowledge diffusion, transfer, and sharing activities among innovative members ${ }^{[10]}$. Previous studies show that the smooth knowledge flow within a network largely depends on the cultural atmosphere among members. On the one hand, cooperative culture enables organizations to form a strong identity, which is conducive to exchange and learning of knowledge ${ }^{[11]}$. Cooperative culture offers a mutual system of learning in which network members can share and exchange knowledge and experiences ${ }^{[12]}$. On the other hand, cooperative culture is conducive to strengthening and improving the relationship between members and establishing a good atmosphere of cooperation. Kim (2016) ${ }^{[13]}$ points out that a good cooperative culture mechanism is beneficial for promoting frequent communication among members, thereby promoting the knowledge flow. Therefore, cooperative culture as a soft constraint significantly promotes knowledge flow. We propose the following hypothesis:

H1: Collaborative culture has a significant positive effect on knowledge flow.

\subsection{The Effect of Network Power on Knowledge Flow}

Network power is the important dimension, which affects the organizations' willingness and behavior to share knowledge. Studies have shown that, network power has a certain impact on the frequency, direction and willingness of knowledge flow (Saxenian,2009 ${ }^{[14]}$, Lieberman, $2013^{[15]}$ ). Turker (2014) ${ }^{[16]}$ points out that network power is the relationship between organizations based on power and its configuration. It is the result of mutual games between actors in the process of participation, interaction and coordination. This process effectively promotes knowledge sharing among members. Kahkonen (2014) ${ }^{[17]}$ indicates that the power of core enterprise affects the formation of cooperative relations and depth of cooperation among members in innovation networks, that is, good network power is conducive to promoting knowledge exchange between members. Wu (2017) ${ }^{[18]}$ studies the influence of core corporate network power on the cooperative behavior of cluster members in the context of Chinese clusters, and find that core corporate network power can actively and effectively guide the behavior of other members and increase the frequency of knowledge exchange between members. Therefore, this paper believes that network power has a positive effect on knowledge flow in the network. Based on the analysis above, we propose Hypothesis 2:

$\mathrm{H} 2$ : Network power has a significant positive effect on knowledge flow

Based on the above analysis, the study explores the effect of cooperative culture and network power on knowledge flow. On the basis of using SEM to verify the hypothesis, we divide cooperative culture into three dimensions: cultural fit, cultural compatibility and reciprocity. Network power is divided into two dimensions: knowledge network and structural power. Then we combine fsQCA method to study the influence of different element combinations on knowledge flow, and propose the theoretical model of this paper. The model is shown in Figure 1.

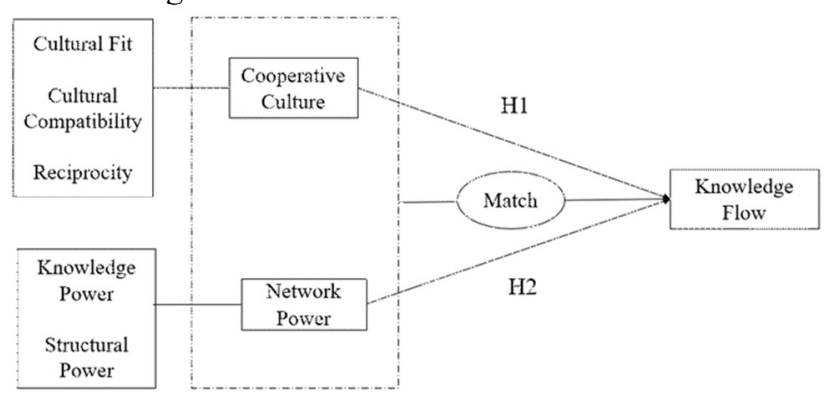

Figure1. Conceptual model

\section{Prepare Research Methods}

\subsection{Data Collection and Samples}

The target samples are enterprises in innovation networks that participate in innovation cooperation. We conducted a pre-test before the formal survey. Of the 155 pre-test questionnaires issued, 80 valid questionnaires were collected. Based on an analysis of the valid questionnaires, we refined the items to finalize the formal questionnaire. The formal survey collected 325 questionnaires. Through a screening of the integrity and validity of the collected questionnaires, those with incomplete data or obvious tendencies were eliminated and 227 valid questionnaires were retained, with an effective response rate of $69.8 \%$.

\subsection{Scales}

The formal questionnaire included three variables: cooperative culture, network power, and knowledge flow. Most of the items on the questionnaire were based on 
existing research and were revised according to real innovation network situations. The questionnaire applied a seven-point Likert scale ranging from 1 ='strongly disagree' to 7 ='strongly agree'

This study measured cooperative culture through three dimensions: cultural fit, cultural compatibility and reciprocity. The cultural fit items refer to Marsden's (1990) ${ }^{[19]}$ research. The cultural compatibility items are inspired by Oliver's (1990) ${ }^{[20]}$ research. The reciprocity items, which measure the degree of mutually benefits reflected by culture, are derived from Li's 2007) ${ }^{[21]}$ research.

Knowledge flow refers to the creation, dissemination and sharing of knowledge among innovation network members. This study measure knowledge flow from two constructs: knowledge creation and knowledge sharing, mainly referring to the research of Lee (2001) ${ }^{[22]}$, Hooff (2004) ${ }^{[23]}$ and Cho's (2004) ${ }^{[24]}$.

This study measured network power from the two constructs: knowledge power and structural power. Knowledge power items, which measure the influence of heterogeneous knowledge resources owned by an enterprise on its power, refer to Latiff's $(2008)^{[25]}$ research. The structural power items, which measure the power generated by a special position in the network structure, refer to Knight's (2005) ${ }^{[26]}$ research.

\subsection{Method Choice}

Structural equation modeling (SEM), a multivariate statistical technique, is used in this study to analyze the data ${ }^{[27]}$. Compared with conventional linear regression, SEM allows comparisons among alternative theoretical models via indexes. It can also define causal relationships among these latent factors ${ }^{[28]}$. Therefore, this paper uses SEM to analyze the linear relationship between cooperative culture, network power and knowledge flow.

Fuzzy-set qualitative comparative (fsQCA). This method is first proposed by Charles Ragin ${ }^{[29]}$. Compared with SEM, QCA can study the overall mechanism of action, not just the independent influence of each element. QCA helps to clearly identify different antecedents and their consistent relationship with the results, and can combine various antecedents with each other based on an objective Boolean algorithm ${ }^{[30]}$. In view of the fact that this paper studies the configuration of different cooperative culture and network power elements that lead to high knowledge flow, fsQCA is a very suitable method. Therefore, this study combines the methods of SEM and fsQCA to explore the relationship between the elements of cooperative culture, network power and knowledge flow.

\section{Results}

\subsection{Hypothesis Testing}

This study utilized SPSS22.0 to examine the reliability and validity of the conceptual model. All items' scores for Cronbach's alpha are higher than 0.80 , and those KMO are higher than 0.8 , showing that the scale has good internal consistency and reliability ${ }^{[31]}$. In addition, the factor load values of all indexes are above 0.5 . These indicators are within acceptable limits, indicating that each latent variable has discriminant validity.

Table 1. Evaluation of the measurement model

\begin{tabular}{|c|c|c|c|c|}
\hline Construct & $\begin{array}{c}\text { Cronbach's } \\
\text { Alpha }\end{array}$ & KMO & $\begin{array}{c}\text { Number } \\
\text { of items }\end{array}$ & $\begin{array}{c}\text { Factorial } \\
\text { loads }\end{array}$ \\
\hline Cooperative culture & 0.849 & 0.818 & 6 & $0.703-0.803$ \\
\hline Network power & 0.883 & 0.870 & 11 & $0.589-0.829$ \\
\hline Knowledge flow & 0.866 & 0.837 & 6 & $0.690-0.807$ \\
\hline
\end{tabular}

This study uses Amos 21.0 to evaluate the fit of the models. The measurement results are shown in Table 2. Both GFI and CFI are greater than $0.7, \lambda 2 / \mathrm{df}<5$, and the RMSEA is close to 0.1. All indicators are within acceptable limits ${ }^{[32]}$. Overall, the overall fit of the models are acceptable.

The hypothesis test results are shown in Table 2. Cooperative culture has a significant positive effect on knowledge flow, and the effect coefficient is 0.612 . Thus, $\mathrm{H} 1$ is supported. Network power also has a significant positive effect on knowledge flow, and the effect coefficient is 0.296. Thus, H2 is supported. Based on the analysis, Hypotheses 1-2 are supported. Cooperative culture and network power can positively promote the knowledge flow.

Table 2. Goodness of fit and hypothesis test results.

\begin{tabular}{|c|c|c|c|c|c|c|c|c|}
\hline Structural path & $\lambda \mathbf{2} / \mathbf{d f}$ & CFI & GFI & RMSEA & Estimate & S.E & $\begin{array}{c}\text { P } \\
\text { Values }\end{array}$ & $\begin{array}{c}\text { Hypothesis } \\
\text { testing }\end{array}$ \\
\hline Cooperative culture->Knowledge flow & 3.193 & 0.906 & 0.891 & 0.099 & 0.612 & 0.076 & $* * *$ & $\begin{array}{c}\text { H1 } \\
\text { supported }\end{array}$ \\
\hline Network power->Knowledge flow & 3.763 & 0.818 & 0.795 & 0.111 & 0.296 & 0.049 & $* * *$ & H2 \\
supported \\
\hline
\end{tabular}

\section{2 fsQCA Results}

\subsubsection{Calibration}

Calibration is a conversion process that converts conventional measurement values into fuzzy set. It is necessary to calibrate the aforementioned variables. In this study, the Likert scale is converted into a fuzzy set by calculating the average of each latent variable item ${ }^{[33]}$. This study uses the criteria of 5\% (Fully out), 95\% (Fully in) and $50 \%$ (Crossover Point) proposed by Ragin to 
calibrate the conditional variables and outcome variables into fuzzy sets. According to related studies (Fiss, 2011) ${ }^{[34]}$, this study set the upper and lower quartiles of each variable and their mean values as qualitative anchor points.

\subsubsection{Analysis of necessary Conditions}

Before analyzing the specific path, it is necessary to check the necessary conditions. In fact, necessary conditions are unhelpful for predicting the outcome, because it might be a common component across all causal recipes in the solutions Ragin,2008). As shown in Table 3, the consistency coefficients of all the conditions are lower than 0.9 , indicating that the conditions above are not necessary conditions for high knowledge flow.

\begin{tabular}{|c|c|c|}
\hline \multicolumn{3}{|c|}{ Table 3. Analysis of necessary conditions } \\
\hline \multirow{2}{*}{ Construct } & \multicolumn{2}{|c|}{ Outcome Variable } \\
\hline & Consistency & Coverage \\
\hline \multicolumn{3}{|c|}{ Cooperative Culture } \\
\hline Cultural Fit & 0.613 & 0.646 \\
\hline$\sim$ Cultural Fit & 0.463 & 0.428 \\
\hline Cultural Compatibility & 0.564 & 0.700 \\
\hline$\sim$ Cultural Compatibility & 0.506 & 0.413 \\
\hline Reciprocity & 0.659 & 0.715 \\
\hline$\sim$ Reciprocity & 0.430 & 0.388 \\
\hline \multicolumn{3}{|c|}{ Network Power } \\
\hline Knowledge Power & 0.642 & 0.683 \\
\hline$\sim$ Knowledge Power & 0.452 & 0.414 \\
\hline Structural Power & 0.670 & 0.684 \\
\hline$\sim$ Structural Power & 0.433 & 0.412 \\
\hline
\end{tabular}

\subsubsection{The fsQCA Solutions}

This study uses fsQCA3.0 software for analysis. we set the consistency and proportional reduction in consistency (PRI) thresholds to 0.8 and 0.7 , respectively. The number of acceptable cases set to 3.4. As shown in the Table 4. We obtained three paths leading to high knowledge flow.

Solution P1 indicates a knowledge reciprocityoriented configuration, which reciprocity and knowledge power as the core conditions. It means that in a network environment where members have an interest relationship, and core enterprises with rich knowledge resources can make reasonable use of knowledge power to support other members. As well as, members can respect each other's values and cultural differences, so that more frequent knowledge flow in the network can be realized.

Solution P2 is a compatible cooperative cultureoriented configuration. Even if the enterprise in a non-core position in the network, as long as it has sufficient heterogeneous knowledge resources. At the same time, cooperative culture can coordinate the relationship between members very well, especially when there is a high degree of cultural compatibility between members, it will also produce high knowledge flow.

Solution P3 is a compatible cultural knowledge fitoriented configuration. Cultural fit and knowledge power are the core conditions, cultural compatibility and structural power are auxiliary conditions. This path shows that in the innovation network oriented by cultural fit, knowledge power is the key to achieving high knowledge flow. While paying attention to values, enterprises must also pay attention to strengthening their own knowledge power to promote the achievement of high knowledge flow.

Table 4. Solutions leading to high knowledge flow

\begin{tabular}{|c|c|c|c|}
\hline \multirow{2}{*}{ Construct } & \multicolumn{3}{|c|}{ High knowledge flow } \\
\hline & $P 1$ & $P 2$ & $P 3$ \\
\hline \multicolumn{4}{|c|}{ Cooperative Culture } \\
\hline Cultural Fit & & $\bullet$ & $\bullet$ \\
\hline Cultural Compatibility & - & $\bullet$ & $\bullet$ \\
\hline Reciprocity & $\bullet$ & - & \\
\hline \multicolumn{4}{|c|}{ Network Power } \\
\hline Knowledge Power & 0 & $\bullet$ & - \\
\hline Structural Power & & & $\bullet$ \\
\hline consistency & 0.862 & 0.842 & 0.873 \\
\hline Raw coverage & 0.349 & 0.33 & 0.297 \\
\hline unique coverage & 0.084 & 0.065 & 0.032 \\
\hline Solution consistency & \multicolumn{3}{|c|}{0.446} \\
\hline Solution coverage & \multicolumn{3}{|c|}{0.842} \\
\hline
\end{tabular}

Note: $=$ core casual condition (present). $=$ peripheral casual condition (present). $\otimes=$ core casual condition(present). $\otimes=$ peripheral casual condition (absent). Blank spaces indicate "don't care."

\section{Discussion}

\subsection{Managerial Implications}

This study offers several managerial implications. Firstly, innovation network management should attach importance to knowledge resource management and rationally regulate resource allocation. The fsQCA result indicates that knowledge power is essential to high knowledge flow. Knowledge resource is the fundamental source of corporate competitive advantage in innovation networks. We should formulate reasonable network standards to encourage enterprises, which hold core 
knowledge resources to provide certain support to other enterprises, and effectively meet the needs of other members for core resources, so as to ensure the development of cooperative enterprises and the entire innovation network.

Secondly, Enterprises should enhance their own network power, enrich cooperation experience and master more resources, knowledge by establishing multiple cooperative relations. In most circumstances, enterprises with higher network power often have better relationship and resource integration capabilities, which can ensure the stability of long-term cooperative relationships between enterprises.

Thirdly, innovation network management should focus on the joint management of network power and cultural environment. In innovation networks, enterprises need to occupy a favorable structural position to obtain key and irreplaceable knowledge resources to enhance its network power. A harmonious cultural atmosphere is conducive to network power plays its role. Enterprises should use network power reasonably according to the specific network environment, so as to better coordinate the distribution of benefits and relationship governance in the network. Further promote knowledge exchange and interaction among members, and promote healthy and stable development of innovation networks.

\subsection{Limitations and Future Research}

This study has the following limitations. Firstly, although the sample is from different enterprises and provinces, it cannot cover all types of enterprises. And the samples are subjective measurements, it is difficult to avoid the result bias that may be caused by the subjectivity of the data. Secondly, this study only discusses the effects of cooperative culture and network power on knowledge flow, without considering the combined effects of other governance mechanisms. In addition, network power in innovation network is not static, and the structure and position of enterprises in networks are also in dynamic change. If the dynamic evolution can be introduced into relevant researches, more meaningful discoveries will be made.

\section{Conlusions}

Based on the sample data of 227 enterprises in innovation networks. This study use the combination of SEM and fsQCA to explore the relationship between cooperative culture, network power and knowledge flow. This paper draws the following conclusions. Firstly, SEM result validate all the hypotheses, indicating that cooperative culture and network power can positively promote the knowledge flow. Secondly, the fsQCA method is used to obtain three paths that lead to high knowledge flow in innovation network, which are "knowledge reciprocityoriented", "cooperative culture-oriented" and "cultural knowledge fit-oriented". These findings are of great significance for promoting the management of innovation networks.

\section{Acknowledgment}

The authors are grateful to the editors of ICEM 2020 for their suggestions for this study.

Funding project: national Natural Science Foundation project "informal Governance Research of Enterprise Innovation Network" (Project number: 71602132); National Natural Science Foundation project "Research on knowledge chain relationship Governance based on the Evolution of Cross-organizational relationships" (Project number: 71571126)

\section{References}

1. Imai, K.B.Y. Systemic Innovation and CrossBorder Networks: Transcending Markets and Hierarchies to Create a New Techno-Economies System. In Conference on Science Technology and Economic Growth; OECD:Paris, France, 1989.

2. James A . Demystifying the role of culture in innovative regional economies $[\mathrm{J}]$. Regional Studies 2005, 39(9) : $1197-1216$.

3. Moran P . Structural vs . relational embeddedness: social capital and managerial performance $[\mathrm{J}]$. Strategic Management Journal, 2005, 26( 12) : 1129-1151.

4. North D C. Institutions, institutional change and economic performance [M]. Cambridge university press, 1990.

5. Capello R, Faggian A. Collective learning and relational capital in local innovation process[J] . Regional Studies, 2005, 39(1): 7587 .

6. Sun Yonglei, Dang Xinghua, Song Jing. Research review and future prospects of the factors affecting the formation of cooperative organization conventions $[\mathrm{J}]$. Foreign Economics and Management, 2014, 36(3): 56-64.

7. Grewal D S. Network power: The social dynamics of globalization[M]. Yale University Press, 2008.

8. Hayek F A. The use of knowledge in society $[\mathrm{J}]$. The American economic review, 1945, 35(4): 519-530.

9. Falzon L, Quintane E, Dunn J, et al. Embedding time in positions: Temporal measures of centrality for social network analysis[J]. Social Networks, 2018, 54: 168-178.

10. Oyemomi O, Liu S, Neaga I, et al. How cultural impact on knowledge sharing contributes to organizational performance: Using the fsQCA approach[J]. Journal of Business Research, 2019, 94: 313-319.

11. Yang Yanping. Research on the Mechanism of Cluster Innovation Network and Regional Cultural Embeddedness-Based on the Theory of Communication Dynamics[J]. Studies in Science of Science, 2015 (1): 146-153.

12. Li R, Du Y F, Tang H J, et al. MNEs' subsidiary HRM 
practices and firm innovative performance: A tacit knowledge approach[J]. Sustainability, 2019, 11(5): 1388.

13. Kim S, Kim H, Kim E. How knowledge flow affects Korean ICT manufacturing firm performance: A focus on open innovation strategy $[\mathrm{J}]$. Technology Analysis \& Strategic Management, 2016, 28(10): 1167-1181.

14. Saxenian, Anna Lee.Origins and dynamics of production networks in Silicon Valley[J].Research Policy, 2009,20(05):423.

15. Lieberman, M. B., \&Asaba, S. . Inventory reduction and productivity growth: A comparison of Japanese and US automotive sectors. Managerial and Decision Economics, 18(2).2013

16. Turker D. Analyzing relational sources of power at the interorganizational communication system[J]. European Management Journal, 2014, 32(3): 509-517.

17. Kähkönen A K. The influence of power position on the depth of collaboration[J]. Supply Chain Management: An International Journal, 2014.

18. Wu Songqiang, Sun Bo, Wang Lu. The influence of the core enterprise network power in the cluster on the cooperative behavior of supporting enterprises: the moderating effect of relational capital[J]. Science \& Technology Progress and Policy, 2017 (13): 81-88.

19. Marsden, T. Towards the Political-Economy of Pluriactivity. J. Rural Stud. 1990, 6, 375-382.

20. Oliver, N. Work Rewards, Work Values, and Organizational Commitment in an Employee-Owned Firm: Evidence from the U.K. Hum. Relat. 1990, 43, 513-526.

21. Li, Z.; Liang, X.; Zhao, L. Relationship between Industrial Cluster Network Structure and Enterprise Innovation Performance. Sci. Res. 2007, 4, 777-782.

22. Lee, J.N. The impact of knowledge sharing, organizational capability and partnership quality on IS outsourcing success. Inf. Manag. 2001, 38, 323335.

23. Van Den Hooffff, B.; De Ridder, J.A. Knowledge sharing in context: The inflfluence of organizational commitment, communication climate and CMC use on knowledge sharing. J. Knowl. Manag. 2004, 8, 117-130.

24. Cho, K.R.; Lee, J. Firm Characteristics and MNC's Intra-Network Knowledge Sharing. Manag. Int. Rev. 2004, 44, 435-455. Ragin, C.C. The Comparative Method: Moving beyond Qualitative and Quantitative Strategies; University of California Press: Berkeley, CA, USA, 2014.

25. Latiff $\mathrm{H}$ S, Hassan A. Rise and fall of knowledge power: An in-depth investigation[J]. Humanomics, 2008,24(1):17-27

26. Knight L, Pye A.Network learning:an empirically derived model of learning by groups of organizations[J] .Human Relations, 2005, 58(3):369 392.

27. Diamantopoulos, A., 1993. Modelling with LISREL, a guide for the uninitiated. Journal of Marketing Management 10 (1-3), 105-136.

28. Hair, J.F., Anderson, R.E., Tatham, R.L., Black, W.C., 1998. In: Multivariate Data Analysis fifth ed PrenticeHall, Upper Saddle River, NJ.

29. Ragin, C.C. The Comparative Method: Moving beyond Qualitative and Quantitative Strategies; University of California Press: Berkeley, CA, USA, 2014.Fiss P C. Building better causal theories: A fuzzy set approach to typologies in organization research[J]. Academy of management journal, 2011, 54(2): 393-420.

30. Hult, G.T.M.; Ketchen, D.J.; Nichols, E.L. An examination of cultural competitiveness and order fulfillment cycle time within supply chains. Acad. Manag. J. 2002, 45, 577-586.

31. Hair, J., Sarstedt, M., Ringle, C. M., \& Gudergan, S. P. (2017). Advanced issues in partial least squares structural equation modeling. California, USA: SAGE Publications.

32. Bagozzi, R.P.; Yi, Y. On the evaluation of structural equation models. J. Acad. Mark. Sci. 1988, 16, 74-94.

33. Ragin, C. C. (2009). Redesigning social inquiry: Fuzzy sets and beyond. University of Chicago Press.

34. Fiss P C. Building better causal theories: A fuzzy set approach to typologies in organization research[J]. Academy of management journal, 2011, 54(2): 393420. 